\title{
Culture of Common Pistachio Present in Central Asia on the Basis of Bio-Ecological and Morphological Features of this Nut-Bearing Species
}

Eshankulov B.I.

State Committee of forestry of the Republic of Uzbekistan

\begin{abstract}
The results of study of Pistachio real- Pistacia vera L. bio-ecological and morphological features. Pistachio real- Pistacia vera $L$. is a nut bearing woody species widespread in the southern mountains of Central Asia.
\end{abstract}

Keywords: Pistacia vera L., Central Asia, bio-ecological, morphological features, , growth and development

\section{Introduction}

Genus Pistacia L. belongs to sumaches familyAnacardiaceae Lindl, combining approximately 20 kinds of small evergreen and deciduous trees and bushes, mainly spreading in subtropical and tropical regions of northern hemisphere on four geographical regions: 1) Eastern Asia 2) Central Asia and Foremost Asia 3) Mediterranean 4) Northern America in each of them grow various types of pistachio, such as P. Terebinthus L., P. Palestina Boiss, P. Khnjuk Stocks, P. Chinensis Bgl, P. Vera L. etc.

In the republics of Central Asia, including Uzbekistan grows only Pistacia vera L- common, honorable or edible. From a great variety of its species only genus Pistachio Vera L. forms edible fruits the so called pistachio nuts and introduced into culture as valuable nut-bearing species.

Pistacia vera $\mathrm{L}$ is a pronounced xerophyte and can grow without irrigation in such arid conditions where other wood species are killed due to moisture deficiencies. Pistachio due to a well-developed root system performs a large waterprotective, soil-protective, anti-mudflow role, improving the microclimate of the surrounding areas.

Currently, areas of natural distribution of common pistachio in the past are defined. The areas corresponding to the biologo-ecological properties of pistachios are determined, on which it is possible to create rain-fed crops taking into account the special purpose of the created plantations. In general, it should be recognized that pistachio has a huge role in the total volume of silvicultural work in the mountains and foothill conditions in the southern mountains of Central Asia.

The role of pistachios in mountain gardening is no less important as in the world market pistachio nuts are more expensive valued than other nut-bearing breeds. It is known that in the countries of the Mediterranean basin (Iran, Turkey, Syria, etc.), the pistachio is called a "golden tree" because of the high incomes it brings, what is more in these countries the main products are obtained not from wild growths, but from garden plantations. The countries of the Mediterranean basin have a thousand-year history of cultivating pistachio in orchards, which are the main sources of existence and well-being, of population, especially in the southern provinces.

Unfortunately, until quite recently, on an ancient homeland in Central Asia hasn't been paid due attention not only to cultivating the garden culture of this valuable nut-bearing breed, but also to preserving the unique natural thickets of pistachios in nature. The first researchers of vegetation in Central Asia as long ago as in the 18th century called the Central Asian mountains "the country of pistachios". Here it stretched from north to south to $800 \mathrm{~km}$, from east to west to $1800 \mathrm{~km}$, according to archaeologists occupying the area, more than 2 million hectares, unfortunately in the modern era, because of unreasonable activity of people (cutting, pasturing of cattle, etc.) does not exceed 300 thousand hectares. Meanwhile, in Central Asia and especially in Uzbekistan, there are real opportunities to restore not only the former area of pistachio distribution by means of cultivation of forest crops, but also by creating them in a garden (plantation) type. Developed by scientists, the basic agrotechnical methods of growing plantations in rainfed foothills and low mountains, based on the biologo ecological and morphological features of common pistachio and the availability of huge empty rainfed territories suitable for growing of drought resistant common pistachio, will allow the implementation of the program for the development of industrial walnut-breeding developed in Uzbekistan, including pistachio-breeding.

Until quite recently, the restoration of pistachio trees in Central Asia was made by foresters by sowing seeds on a permanent place. Besides, seed selection was not carried out, moreover, pistachios, because of their dioeciousness, do not preserve the original properties of the mother plant in seed progeny. In this case, by sowing seeds on a permanent place, surplus thickened crops were cultivated, with the placement of 3-4, even 6-8 thousand plants on 1 hectare. Due to the fact that pistachio lacks the ability to self-thinning, it is necessary to thin it out in rows, with transfer of forest thickened crops into productive plantations of forest type with the placement of no more than $300-400$ plants per hectare.

As seen from research of Central Asian scientists (S.M.Ablaeva, G.M.Chernova, etc.) proper estimation of density of pistachio plants placement can ensure its high assimilative activity and provide normal productivity of this 


\section{International Journal of Science and Research (IJSR) \\ ISSN (Online): 2319-7064}

Index Copernicus Value (2016): 79.57 | Impact Factor (2015): 6.391

kind. On rare trees placement nearly for twice increase accumulation of organic mass by over-ground part of pistachio in comparison with thickened planting.

From data given in table 1 it follows that with the reduction of trees numbers the soil moisture preserves better. Thus, in placement of 4 thousand of plants per ha it makes $5,1 \%$, in $277-8,9 \%$.High moisture of soil, especially in spring period, increase mineral nutrition of plants which provides by more intensive accretion of stalk both on height and on diameter in comparison with thickened planting. The highest per cent of plants at the age of 15, grown in non-irrigated foothill areas of Uzbekistan, entered into fruit-bearing period was noted in rare placement- 277 trees per ha-37\% in comparison with 9 and $11 \%$ in planting. There given a table of placement of 2 and 4 thousand un / ha.

That is why without any damage for forest reclamation significance of creating pistachio culture in non-irrigated areas of Uzbekistan foothills, the number of

Table 1: The influence of density placement on soil moisture, growth and development of pistachio (15 years old)

\begin{tabular}{|c|c|c|c|c|c|}
\hline $\begin{array}{c}\text { Number of plants, } \\
\text { un / ha }\end{array}$ & $\begin{array}{c}\text { Average moisture } \\
\text { of soil at the depth } \\
\text { of 0-26 cm, \% }\end{array}$ & $\begin{array}{c}\text { Mass of over- } \\
\text { ground part of one } \\
\text { plant, } \mathrm{kg}\end{array}$ & $\begin{array}{c}\text { Average stalk } \\
\text { accretion on } \\
\text { height, } \mathrm{cm}\end{array}$ & $\begin{array}{c}\text { Average stalk } \\
\text { accretion on } \\
\text { diameter, mm }\end{array}$ & $\begin{array}{c}\text { Number of fruit- } \\
\text { bearing trees, \% }\end{array}$ \\
\hline 4000 & 5,1 & 8,2 & 12 & 9 & 9 \\
\hline 2000 & 7,6 & 10,9 & 17 & 14 & 11 \\
\hline 1000 & 8,1 & 14,1 & 21 & 22 & 28 \\
\hline 277 & 8,9 & 16,2 & 24 & 29 & 37 \\
\hline
\end{tabular}

sowing places must be no more than 400 units per ha and in gardening (plantation) cultures - 150-200. This conformed with schemes of pistachio plants placement in gardens of foreign countries (Turkey, Iran, USA) where accepted distance between trees are 9x9 and even 10x10 m.

Besides sowing seeds on a permanent place, is the laying of plantations of pistachios by planting seedlings grown in specially prepared containers with a closed root system (PMCR) is an important agrotechnical method. Containers are prepared from polyethylene film with dimensions of $5 \times 25 \mathrm{~cm}, 15 \times 30 \mathrm{~cm}, 20 \times 40 \mathrm{~cm}$. At the same time, small holes are punched in the bottom part of the containers for drainage purposes, after which they are filled with a soil substrate consisting of a mixture of 3 parts of ordinary (unsalted) soil and 1 part of rotten manure. One seed is sown into each container to a depth of 1-2 cm.

Seeds for sowing are prepared by stratification method (seed preparation for sowing).

Collection of seeds is carried out during their full maturation (I-III decade of August). Seeds are the pistachio nuts themselves. Prepared nuts are cleaned from pericarps for 1-2 days, mixed with moist, well-washed river sand, in a ratio of 1: 5 (one part of seeds, five parts of sand). Then all this mixture is aged for 30-40 days in trenches in the open ground. The seed that is ready for sowing is the nut that begins sprouting in which appeared rootlet.
PMPC is grown at the end of winter or early spring in greenhouse-type premises before transplanting them to a permanent place on the plantation. It is important to avoid late-spring frosts that can kill tender plants in using this kind of planting.

The application of the above-mentioned technology, developed by the scientific research institute of forestry (initiated by Nikolay L.V.) will allow to extend the time for laying plantations (6-7 times), to reduce seed consumption, to improve the survival of crops not only in the conditions of Uzbekistan, but also in other regions of Central Asia, the soil in the containers is abundantly wetted with water 6-8 hours before planting, then they are cut along the suture from bottom to top.

Regardless of the weather conditions, inlaying plantations by using PMCR, in any case, it is necessary to perform postplanting, local watering, at a rate of 1-1.5 1. of water per plant.

Taking into account that the basis for the high adaptation of common pistachio trees to the conditions of the environment is powerfully developing two-level (horizontal and vertical) root system, the cultivation of seedlings in containers with a closed root system of $20 \times 40 \mathrm{~cm}$ size is more efficient and effective, owing to more developed tap roots in seedlings of the given size grown in containers. (Table 2).

Table 2: The results of growing common pistachio seedlings present in containers with a closed root (PMCR) SRIF, Tashkent (Uzbekistan)

\begin{tabular}{|c|c|c|c|c|c|c|}
\hline \multirow[t]{2}{*}{ Variants } & \multirow[t]{2}{*}{$\begin{array}{c}\text { Container sizes, } \\
\mathrm{cm}\end{array}$} & \multirow{2}{*}{$\begin{array}{l}\text { Length of tap } \\
\text { root of seedling } \\
\text { in container } x\end{array}$} & \multicolumn{2}{|c|}{$\begin{array}{c}\text { Seedling's size before } \\
\text { planting }\end{array}$} & \multirow{2}{*}{$\begin{array}{l}\text { Survivability after } \\
\text { planting into soil } \\
\text { October }\end{array}$} & \multirow[t]{2}{*}{$\begin{array}{l}\text { \%survivability } \\
\text { to control }\end{array}$} \\
\hline & & & Height $\mathrm{cm}$ & $\begin{array}{c}\text { Diameter of } \\
\text { stem, mm }\end{array}$ & & \\
\hline 1 (control) & $5 \times 25$ & 8 & 10 & 2 & 78 & 100 \\
\hline 2 & $10 \times 25$ & 12 & 12 & 3 & 85 & 109 \\
\hline 3 & $15 \times 30$ & 18 & 15 & 4 & 88 & 113 \\
\hline 4 & $20 \times 40$ & 22 & 17 & 4 & 95 & 122 \\
\hline
\end{tabular}

Thus, it is necessary to note that the significance of pistachios in growing of plantations in the southern mountains of Central Asia is invaluable. It is the most perspective breed in afforestation of foothills and low dry mountains. It is unpretentious for soil and caring, well adapted for cultivation in various natural and climatic zones

\section{Volume 6 Issue 12, December 2017}




\section{International Journal of Science and Research (IJSR) \\ ISSN (Online): 2319-7064}

Index Copernicus Value (2016): 79.57 | Impact Factor (2015): 6.391

throughout the Central Asian region thanks to a powerful root system. It is an indispensable breed for the protection of soil from water erosion on mountain slopes.

Therefore, not only the creation of new plantings of this valuable nut-bearing breed, but also the preservation of natural populations, should be an important state task.

As seen from data given in table 1 plants, grown in containers with sizes no less than $15 \times 30 \mathrm{~cm}$ (till 20x40) are distinguished by more intensive development of tap root in seedlings, which correspondingly possess by higher indexes on height and diameter of stems and also their survivability are better in planting to ground for $13-20 \%$ in comparison with control.

\section{References}

[1] Ablaev S.M. Experiment of pistachio culture in Uzbekistan. Works of Tashkent agricultural institutePub. 9, 1957. p.p. 51-57.

[2] Popov K.P. Pistachio in Central Asia. Ashkhabad, 1979. p. 159

[3] Chernova G.M. Perspectives of walnut breeding in Central Asia. Biological and rational use of

[4] Single in the world nut-fruit forests of South Kirgizistan. Materials of conference. 4-8

[5] September. 1995. Bishkek, 1996. p.p. 66-67.

Note: PMCR - planting material with closed root system 